\title{
Distribution of immunoreactive endothelin in the lungs of mice during respiratory viral infection
}

\author{
M.J. Carr*, L.J. Spalding*, R.G. Goldie*+, P.J. Henry*
}

Distribution of immunoreactive endothelin in the lungs of mice during respiratory viral infection. M.J. Carr, L.J. Spalding, R.G. Goldie, P.J. Henry. (OERS Journals Ltd 1998.

ABSTRACT: Respiratory tract viral infections are associated with the generation of a wide array of pro-inflammatory cytokines, some of which enhance the release of the potent airway smooth muscle spasmogen, endothelin, from respiratory epithelial cells in tissue culture. The aim of this study was to determine whether the content and distribution of immunoreactive endothelin in the intact murine lung is increased during the course of a respiratory tract viral infection.

Mice were inoculated intranasally with Influenza A/PR-8/34 virus or sterile vehicle and at various days postinoculation were sacrificed, and their lungs processed for either fluorescence immunohistochemistry with rabbit anti-endothelin sera or measurement of immunoreactive endothelin with an enzyme-linked immunosorbent assay (ELISA).

At 2 and 4 days postinoculation, the content of immunoreactive endothelin in lung extracts of virus-infected mice was approximately twice that present in lung extracts from control mice $(n=3-4, p<0.05)$. Consistent with this, an increased intensity and broader distribution of fluorescent immunohistochemical staining for endothelin was observed in the airway epithelium of the trachea and intrapulmonary airways of virus-infected mice.

This study has clearly demonstrated that respiratory tract viral infection is associated with an increased content and broader distribution of immunoreactive endothelin within the lungs of mice. Whether the elevated content of endothelin contributes to the symptoms of virus-induced hyperresponsiveness or to virus-induced exacerbations of asthma remains to be established.

Eur Respir J 1998; 11: 79-85.
*Dept of Pharmacology, incorporating the +Biomedical Confocal Microscopy Research Centre, University of Western Australia, Nedlands, Western Australia, 6907.

Correspondence: P.J. Henry

Dept of Pharmacology

University of Western Australia

Nedlands, Western Australia, 6907

Keywords: Endothelin

Influenza A/PR-8/34

mice

respiratory viral infection

Received: May 271997

Accepted after revision September 271997

This research was supported by the $\mathrm{Na}$ tional Health and Medical Research Council of Australia.
The endothelins are a family of three endogenous, spasmogenic isopeptides designated endothelin-1, endothelin2 and endothelin-3 [1]. The airway epithelium is believed to be an important source of the endothelins in the airway wall [2] although other cell types within the lung such as pulmonary macrophages [3] can also produce and release endothelin peptides. The physiological roles of the endothelins in the lung are yet to be clearly established, although endothelin receptors have been localized to a variety of structures within the airway wall, including airway smooth muscle, nerve trunks, submucosal glands and interpulmonary blood vessels [4]. Particularly high densities of endothelin $\mathrm{A}$ and $\mathrm{B}\left(\mathrm{ET}_{\mathrm{A}}\right.$ and $\left.\mathrm{ET}_{\mathrm{B}}\right)$ receptors have been localized to airway smooth muscle and both of these receptor subtypes subserve contraction [4]. The en-dothelins may also influence airway smooth muscle tone indirectly by augmenting cholinergic nerve-mediated airway smooth muscle contractions [5] and by the release of secondary mediators such as platelet-activating factor and thromboxane [6]. There is a growing body of evidence suggesting that these effects contribute to airways obstruction during exacerbations of asthma [7]. For example, a number of studies have reported markedly elevated levels of endothelin immunoreactivity in the bronchoalveolar lavage fluid and in respiratory epithelial cells of biopsy specimens obtained from subjects with symptomatic asthma [8, 9]. Similarly, elevated levels of endothelin-like immunoreactivity were found in bronchoalveolar lavage fluid of sensitized guinea-pigs following allergen provocation [10]. Moreover, the administration of endothelin receptor antagonists provided significant protection against decreased airway conductance associated with antigen challenge of ovalbumin-sensitized guinea-pigs [11] and partially attenuated the hyperresponsiveness associated with the late response in allergic sheep [12].

Respiratory tract infections with viruses such as Parainfluenza and Influenza A can precipitate episodes of wheezing in asthmatics and have been associated with the induction of bronchial hyperresponsiveness in otherwise healthy individuals [13]. The reasons for this association are poorly understood, but seem to involve a variety of factors including virus-induced damage of respiratory epithelial cells and inflammation of the airways [13]. Interestingly, some of the pro-inflammatory cytokines present in bronchoalveolar lavage fluid of mice with Influenza A/ PR- 8/34 virus infection [14], have been reported to enhance the release of endothelin- 1 from respiratory epithelial cells in culture [15]. However, despite this apparent association, it is currently unknown if the levels of endothe-lins in the airways are indeed elevated during res- 
piratory tract viral infection. Thus, the aim of the current study was to determine the content and characterize the distribu- tion of immunoreactive endothelin in the lungs of mice during respiratory tract infection with Influenza $\mathrm{A} / \mathrm{PR}-8 / 34$ virus.

\section{Materials and methods}

\section{Virus stock and inoculation of mice}

Influenza $\mathrm{A} / \mathrm{PR}-8 / 34$ virus was grown in the allantoic fluid of 10 day old embryonated chicken eggs at $37^{\circ} \mathrm{C}$ for 3 days as described previously [16]. The allantoic fluid was harvested and contained $2.7 \times 10^{6}$ egg infectious doses (EID50) of virus per millilitre as determined by the method of allantois-on-shell titration for infectivity [17]. The virus stock was stored in $0.5 \mathrm{~mL}$ aliquots at $-85^{\circ} \mathrm{C}$. Eight week old male $\mathrm{CBA} / \mathrm{CaH}$ mice, specified pathogen free, were obtained from the Animal Resources Centre (Perth, Australia), housed in a controlled environment and received food and water ad libitum. Mice were anaesthetised (50 mg.kg-1 pentobarbitone sodium, i.p.) and intranasal- ly inoculated [18] with $15 \mu \mathrm{L}$ of fluid containing 1,000 EID50 of Influenza A/PR-8/34 virus or $15 \mu \mathrm{L}$ of a 1 in 40 dilution of the allantoic fluid from virus-free chicken eggs (control mice). This experimental protocol was approved by the University of Western Australia Animal Experimentation Ethics Committee.

\section{Extraction of endothelin from lung tissue}

At 2, 4 and 8 days postinoculation, groups of control and virus-inoculated mice were anaesthesized $\left(80 \mathrm{mg} \cdot \mathrm{kg}^{-1}\right.$ pentobarbitone sodium, i.p.), killed by exsanguination and the lungs removed. Lungs were homogenized with glass/ glass tissue homogenizers in a buffer containing $1 \mathrm{M}$ acetic acid and $1 \mu \mathrm{g} \cdot \mathrm{mL}^{-1}$ of pepstatin A (Sigma Chemical Co., St Louis, USA) at a ratio of $10 \mathrm{~mL}$ buffer.g wet tissue1. Lung homogenates were then incubated in a boiling water bath for $10 \mathrm{~min}$ to inactivate proteolytic en-zymes, cooled to $4^{\circ} \mathrm{C}$ and centrifuged at $100,000 \times \mathrm{g}$ for $20 \mathrm{~min}$. The resulting supernatants were frozen and stored at $-85^{\circ} \mathrm{C}$. Immunoreactive endothelin was extracted from tissue supernatants as described previously [19]. Briefly, C18 Sep-Pak cartridges (Waters, Milford, USA) were pretreated with $5 \mathrm{~mL}$ of $90 \%$ acetonitrile (ACN) in $1 \%$ trifluroacetic acid (TFA) followed by $5 \mathrm{~mL}$ of $25 \% \mathrm{ACN}$ in $1 \%$ TFA. Samples $(100 \mu \mathrm{L}$ of lung supernatant diluted with $100 \mu \mathrm{L}$ of $1 \%$ TFA and $200 \mu \mathrm{L}$ of $50 \%$ ACN) were then applied to pretreated C18 Sep-Pak cartridges. After sample application the cartridge was washed sequentially with $20 \mathrm{~mL}$ of $25 \%$ ACN in $1 \%$ TFA, $10 \mathrm{~mL}$ of water and $10 \mathrm{~mL}$ of $50 \%$ methanol. Immunoreactive endothelin was eluted with $16 \mathrm{~mL}$ of $50 \%$ methanol in $4 \%$ acetic acid. Eluted samples were then frozen at $-85^{\circ} \mathrm{C}$ and dried under vacuum in a freeze drier unit (Model FD3; Dynavac, Melbourne, Australia). Dried samples were reconstituted in sample buffer supplied with the enzyme-linked immunosorbent assay (ELISA) kit (Cayman Chemical Co., Ann Arbor, USA) and the assay performed in accordance with the manufacturers instructions. The antibodies used in this assay cross-react with endothelin-1, endothelin-2 and endothelin-3, but not with big endothelins.

\section{Fluorescence immunohistochemistry}

At 2, 4 and 8 days postinoculation, groups of control and virus-inoculated mice were anaesthesized $\left(80 \mathrm{mg} \cdot \mathrm{kg}^{-1}\right.$ pentobarbitone sodium, i.p.) and their lungs perfused in situ with heparinized saline $\left(15 \mathrm{IU} \cdot \mathrm{mL}^{-1}\right)$ followed by picric acid-paraformaldehyde fixative $(20 \mathrm{~g}$ of paraformaldehyde and $150 \mathrm{~mL}$ of a saturated aqueous picric acid solution per $1,000 \mathrm{~mL}$ of phosphate buffer, $\mathrm{pH}$ 7.3). Lung and tracheal tissues were removed and placed in fixative for a further $2 \mathrm{~h}$ at $4^{\circ} \mathrm{C}$. Fixed tissues were then washed and stored at $4{ }^{\circ} \mathrm{C}$ in a phosphate buffer containing $15 \%$ sucrose and $0.01 \%$ sodium azide before being embedded in paraffin. Tissue sections $(5 \mu \mathrm{m})$ were cut and mounted onto gelatin chromalum-coated glass microscope slides. Mounted sections were dewaxed in xylene, dehydrated in ethanol, rinsed in distilled water and prepared for histopathological evaluation or immunostaining. For histopathological evaluation, slide-mounted tissue sections were stained with Gill's haematoxylin, dehydrated in ethanol, cleared in xylene and mounted (Depex, BDH, Poole, UK) for light microscopy. Sections were immunostained using a modification of a previously described technique [2]. Slide-mounted tissue sections were pre-incubated for $1 \mathrm{~h}$ at $22^{\circ} \mathrm{C}$ with $10 \%$ normal goat sera diluted in a $50 \mathrm{mM}$ Tris- $\mathrm{HCl}$ buffer containing $0.1 \%$ Triton-X100 (blocking buffer) followed by incubation overnight at $4{ }^{\circ} \mathrm{C}$ with primary antibody (rabbit anti-endothelin sera, gift from the late D. Springall, Dept of Histochemistry, Royal Postgraduate Medical School, London) diluted (1 in 1,000) in a buffer containing $3 \%$ bovine serum albumin (Sigma), $0.9 \% \mathrm{NaCl}$ and $170 \mathrm{mM}$ Tris-HCl (IHC buffer). Following overnight incubation, sections were washed in two changes of wash buffer $(0.9 \% \mathrm{NaCl}, 50 \mathrm{mM}$ Tris- $\mathrm{HCl})$ for $20 \mathrm{~min}$ at $22^{\circ} \mathrm{C}$ followed by incubation for $1 \mathrm{~h}$ at $37^{\circ} \mathrm{C}$ with alkaline phosphatase-labelled goat anti-rabbit immunoglobulin (IgG) (Sigma) diluted (1 in 100) with blocking buffer. After a 20 min rinse in wash buffer, tissue sections were rinsed in an alkaline Tris-HCl buffer $(\mathrm{pH}$ 8.2) followed by incubation with Vector®Red alkaline phosphatase substrate (Vector Laboratories, Burlingame, USA) for 17 min. Levamisol $(1 \mathrm{mM})$ was included in the reaction mixture to inhibit endogenous alkaline phosphatase. The red precipitate formed in this reaction is visible using standard visible light and fluorescence microscopes. Following a 5 min wash in tap water, tissue sections were dehydrated in ethanol, cleared in xylene and mounted with DePeX (BDH) for fluorescence microscopy.

\section{Statistical analysis}

Differences between treatment means were assessed by analysis of variance (SigmaStat; Jandel Scientific, San Rafael, USA) followed by a modified t statistic [20]. The content of immunoreactive endothelin in the lungs of control and virus-inoculated mice were expressed as picogrammes per lung. A p-value of less than 0.05 was considered statistically significant. 


\section{Results}

\section{General effects of Influenza A/PR-8/34 virus infection}

Intranasal inoculation of mice with 1000 EID50 of Influenza A/PR-8/34 virus caused a nonfatal infection of the respiratory tract which was monitored for periods up to 8 days postinoculation. The general appearance and behaviour of mice during the initial 4 days following inoculation with virus was indistinguishable from that of control mice. However, by day 8 postinoculation, virusinoculated mice were noticeably less active than control mice and macroscopic examination of the lungs from these mice revealed large plum coloured lesions in one or more lung lobes. Furthermore, as shown in figure 1 the mean wet weight of lungs from these mice was approximately twice that of control mouse lungs, consistent with the development of peripheral lung infection, oedema and inflammation.

\section{Histopathology of Influenza A/PR-8/34 virus infection}

Light microscopic examination of lung tissue sections from mice inoculated intranasally with control solution revealed no signs of inflammation. In contrast, examination of tissue sections from the lungs of Influenza A/PR-8/34 virus-inoculated mice revealed morphological characteristics consistent with viral infection. As reported previously [21], fragmentation of the epithelial lining associated with large airways, including the trachea, was observed at 2 days postinoculation. At 4 days postinoculation, lung tissue sections from virus-inoculated mice were characterized by multiple inflammatory foci and marked, widespread degeneration of respiratory epithelial cells from many airways of varying sizes (fig. 2). In addition, many airways within these lung sections were occluded with desquamated epithelial cells and other cellular debris. Large areas of peripheral lung tissue from virus-inoculated mice at 8 days postinoculation were congested and infiltrated with large and small mononuclear inflammatory cells. These findings are consistent with our previous observations regarding the rapid proliferation of Influenza
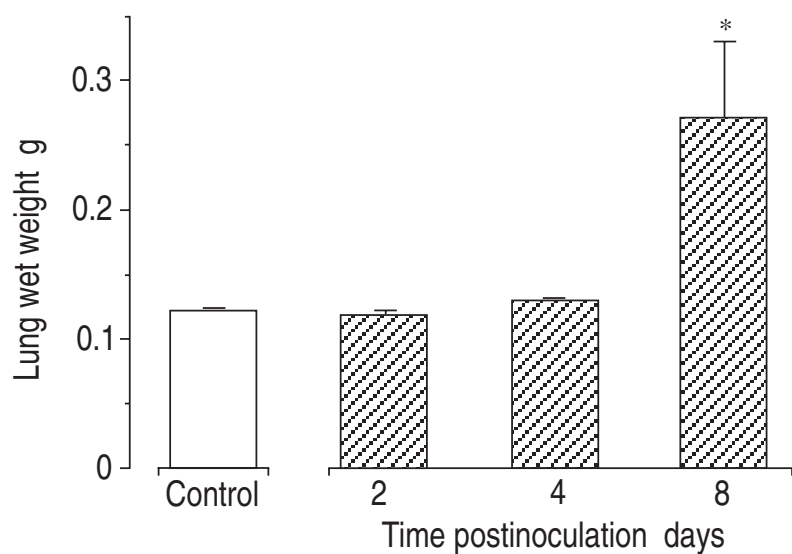

Fig. 1. - Influence of respiratory tract viral infection on lung weight. Lung wet weights of control mice $(\square$; combined data from 2,4 and 8 days postinoculation, $n=11$ ) and mice inoculated with Influenza A/ PR-8/34 virus $(Z 2) 2,4$ or 8 days $(n=4)$ postinoculation. Data are presented as mean \pm SEM. *: $\mathrm{p}<0.05$ compared with control.

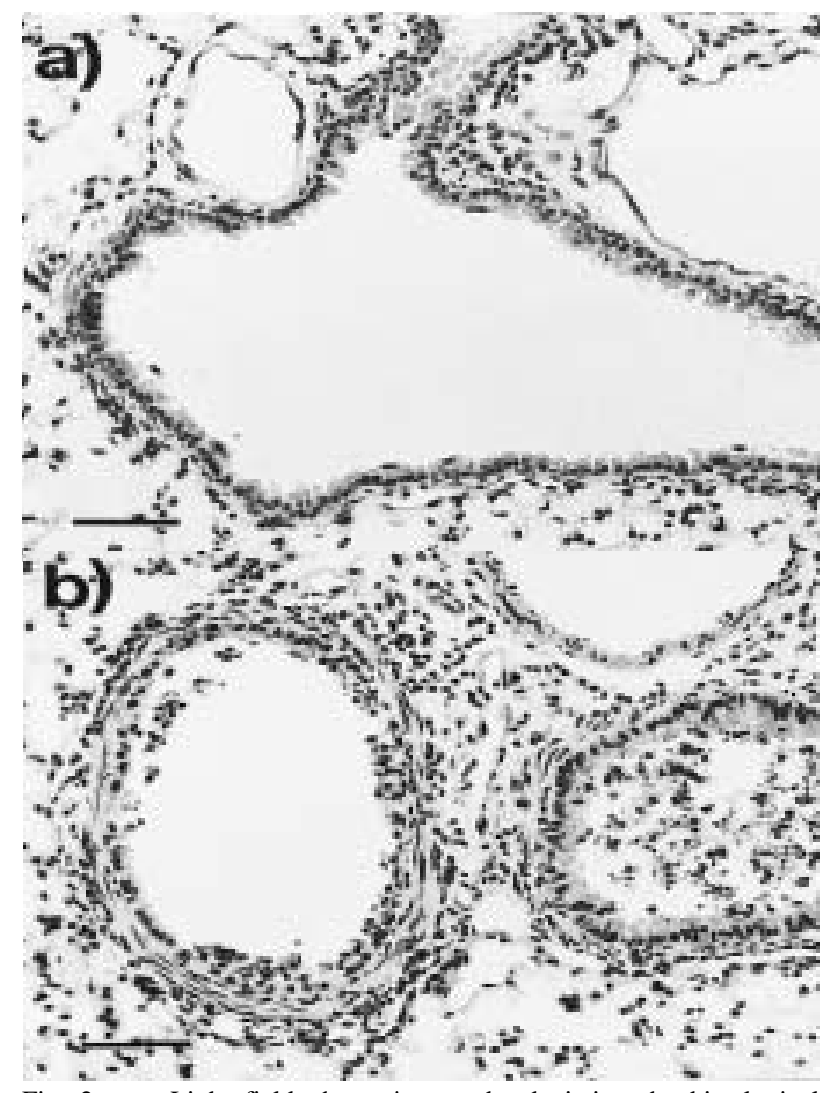

Fig. 2. - Light field photomicrographs depicting the histological appearance of peripheral lung taken from a) control and b) Influenza A/ PR-8/34 virus-infected mice at 4 days postinoculation. Scale bar=50 $\mu \mathrm{m}$.

A/PR-8/34 virus in the trachea of mice during the initial 2 days postinoculation and peak lung viral titres at 4-6 days postinoculation [22].

Content of immunoreactive endothelin in the lungs of control and virus-inoculated mice

Similar levels of immunoreactive endothelin were present in lung extracts from control mice at 2, 4 and 8 days

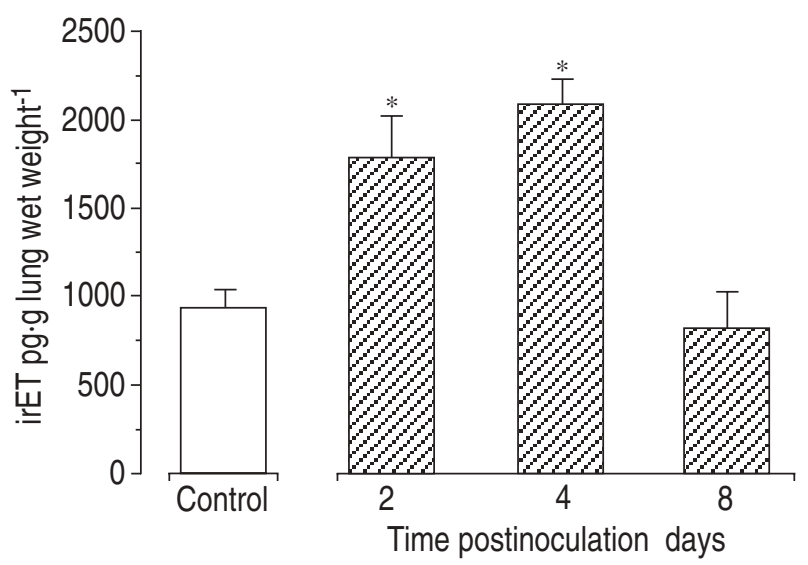

Fig. 3. - Influence of respiratory tract viral infection on levels of immunoreactive endothelin in the lungs of mice. Levels of immunoreactive endothelin (irET) in the lungs of uninfected control mice $(\square$; combined data from 2, 4 and 8 days postinoculation, $\mathrm{n}=11$ ) and Influenza A/PR-8/34 virus inoculated mice $(Z 2)$ at 2,4 or 8 days $(n=4)$ postinoculation. Data are presented as mean \pm SEM. *: $\mathrm{p}<0.05$ compared with control. 

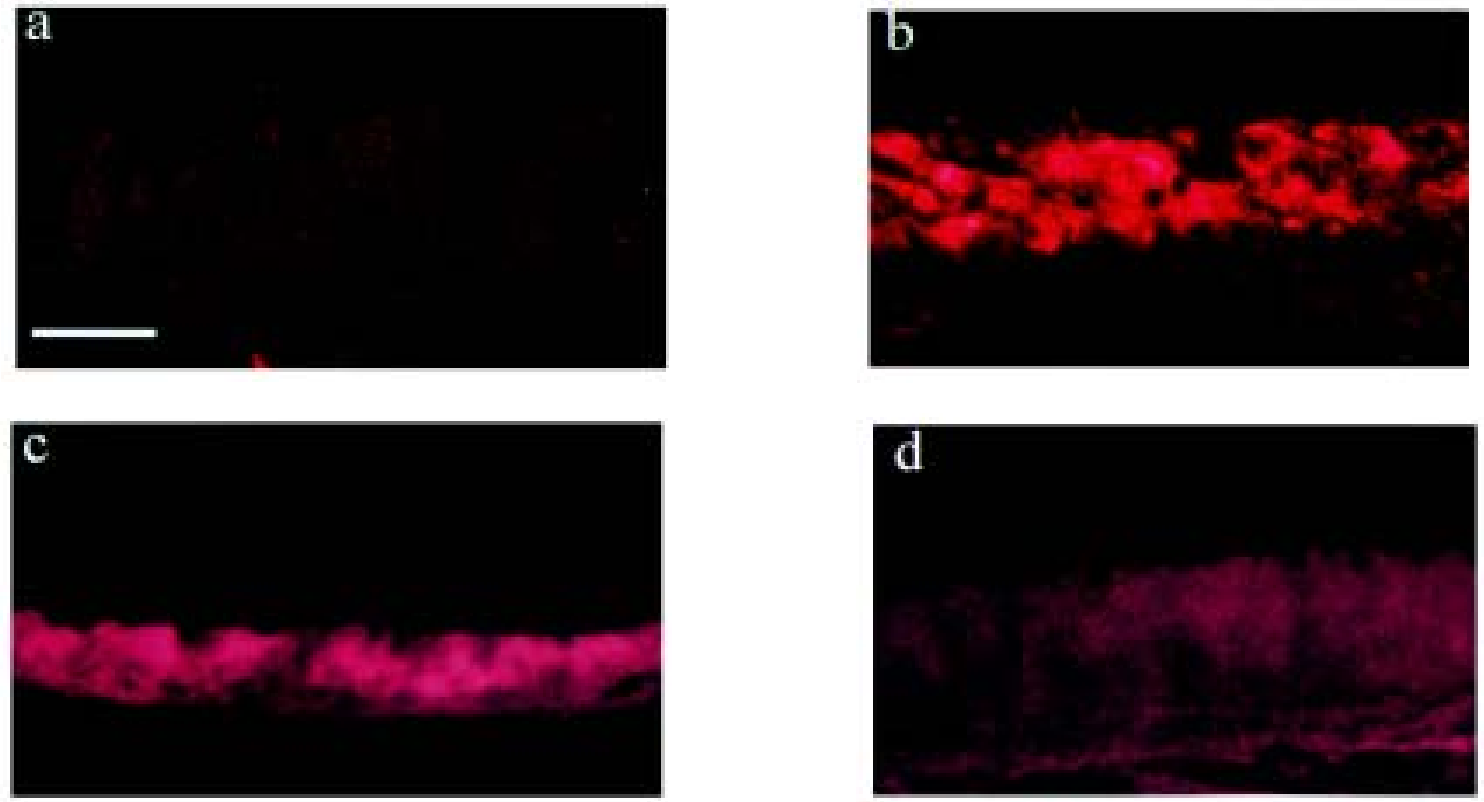

Fig. 4. - Fluorescence photomicrographs depicting the distribution of immunoreactive endothelin associated with the tracheal epithelium of a) control, and Influenza A/PR-8/34 virus infected mice at b) 2, c) 4 and d) 8 days postinoculation. Scale bar $=20 \mu \mathrm{m}$. The anti-endothelin antibody used in this study cross reacts with endothelin-1,2 and 3.
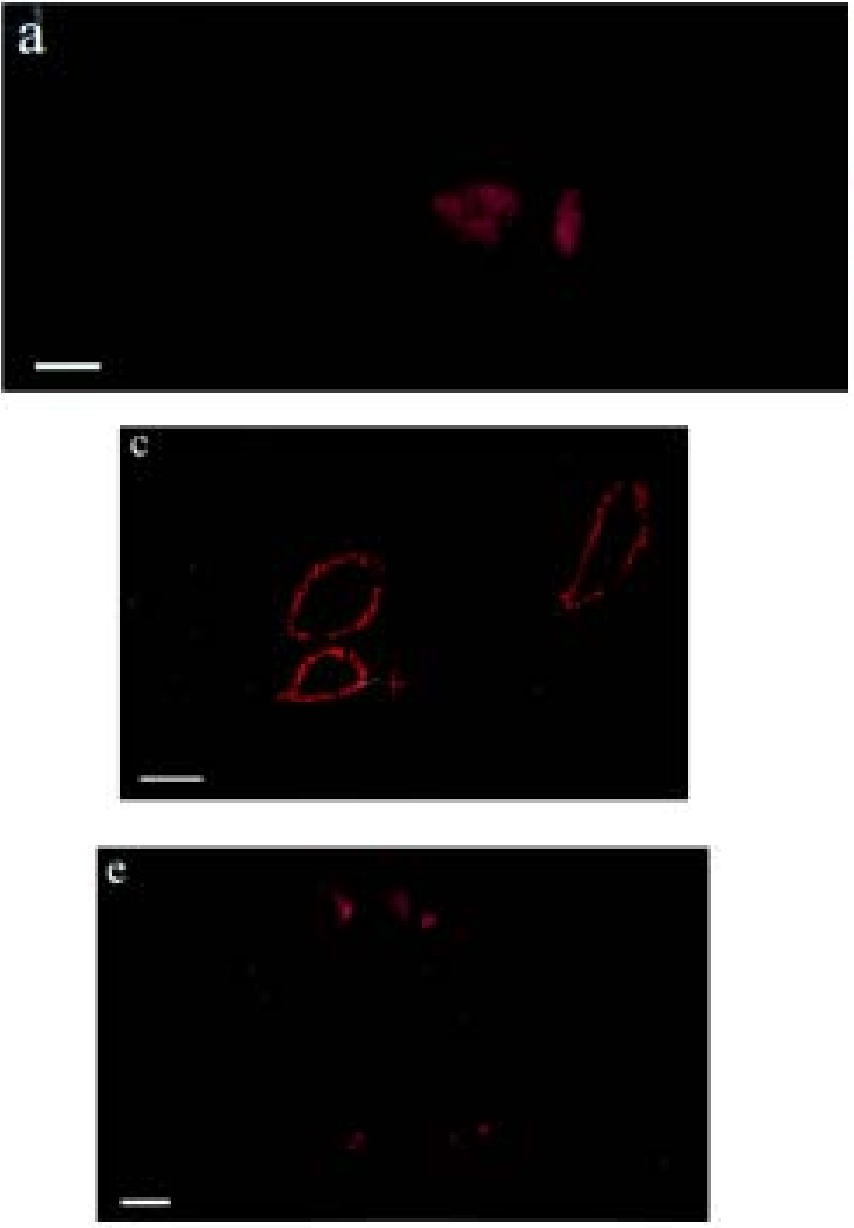
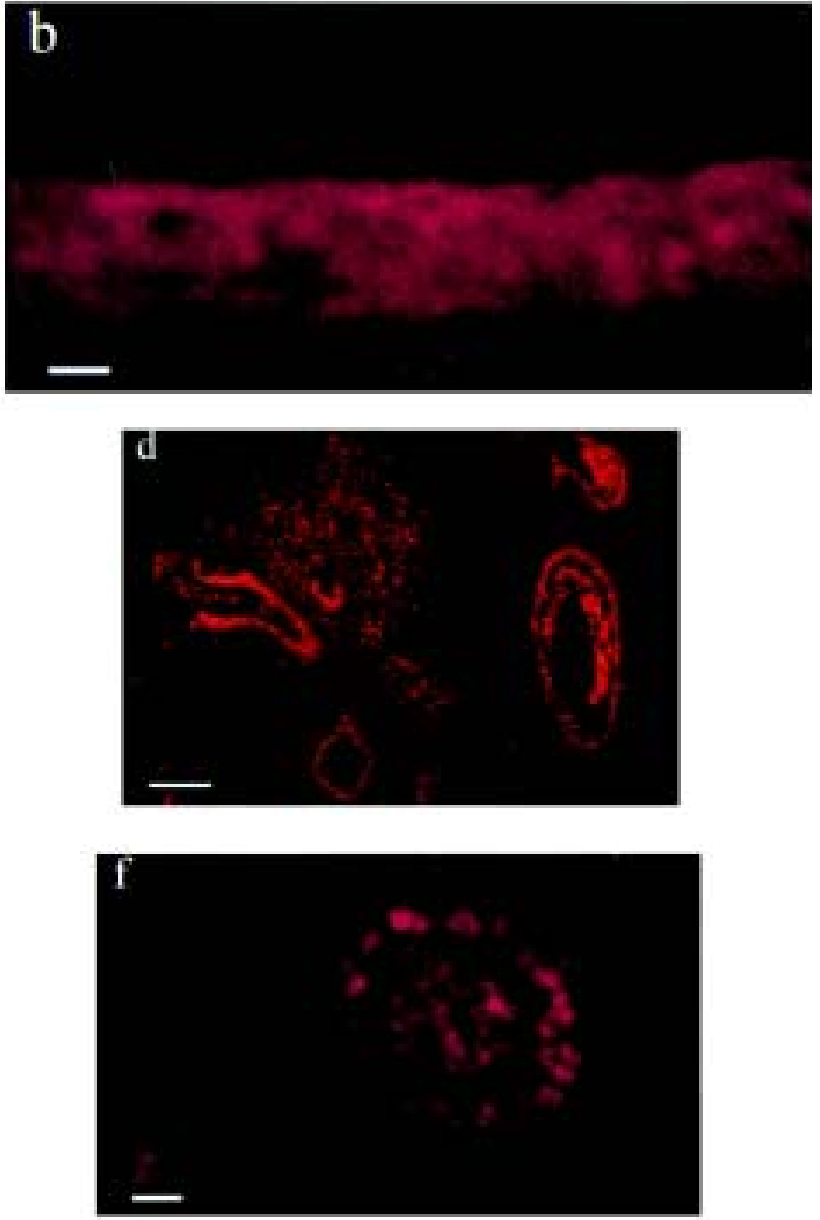

Fig. 5. - Fluorescence photomicrographs depicting the distribution of immunoreactive endothelin associated with the epithelium of a) and b) large, c) and d) medium, and e) and f) small airways in lung tissue sections from control (a, c and e) and Influenza A/PR-8/34 virus-infected mice at b) 2 , d) 4 and f) 8 days postinoculation. Internal scale bars: a) and b) $=10 \mu \mathrm{m}$; ) and d) $=100 \mu \mathrm{m}$; e) and f) $=50 \mu \mathrm{m}$. 
postinoculation. However, viral infection was associated with significantly elevated levels of endothelin immunoreactivity. At 2 and 4 days postinoculation, the level of immunoreactive endothelin in lung extracts of virus-infected mice were approximately twice those present in lung extracts from control mice (fig. 3). The level of immunoreactive endothelin in the lungs of mice 8 days after inoculation with virus was similar to that of control mice.

\section{Distribution of immunoreactive endothelin in the lungs of control and virus-inoculated mice}

Immunoreactive endothelin in lung tissue sections from control mice was present predominantly in the epithe-
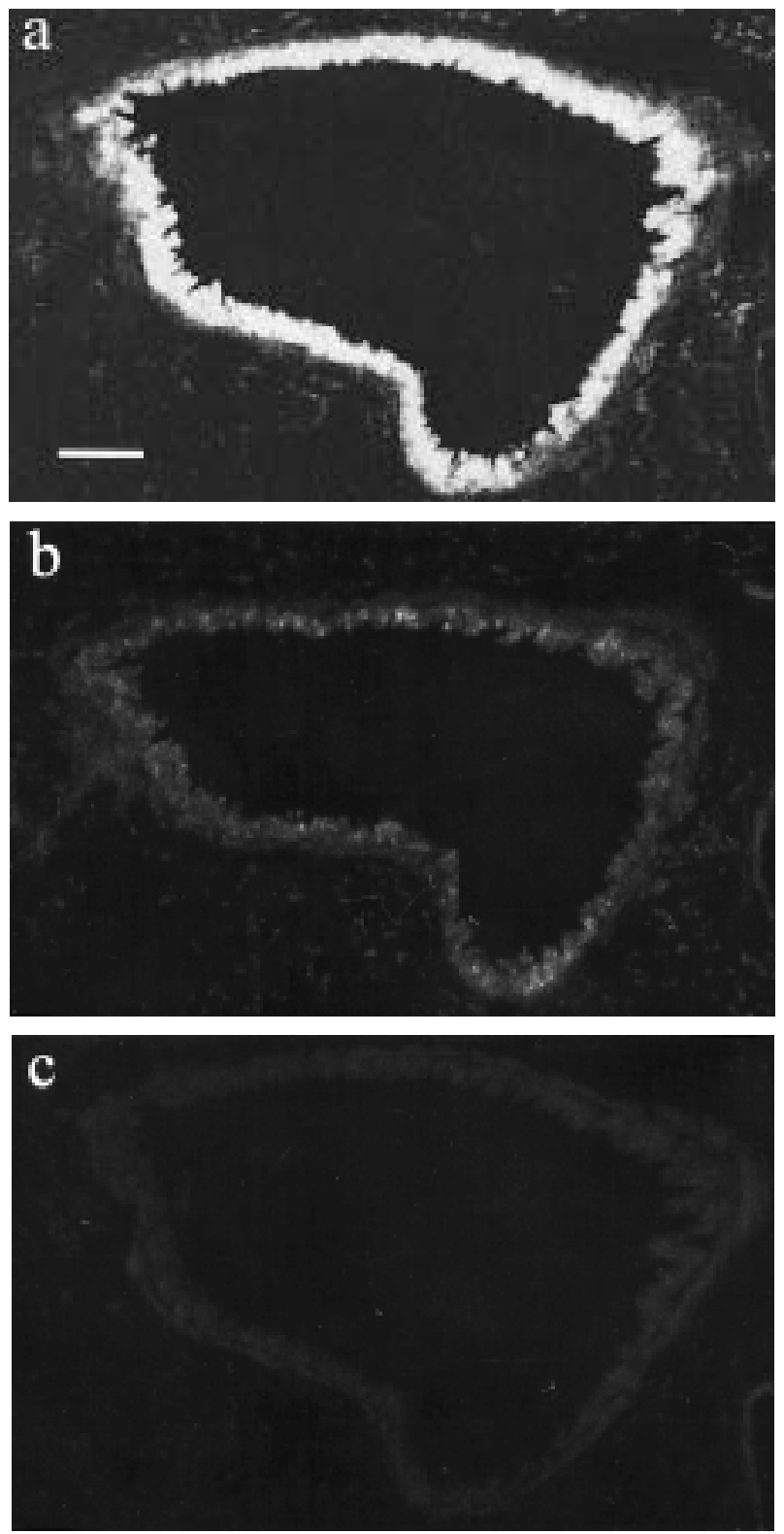

Fig. 6. - Fluorescence photomicrographs depicting the immunofluorescence for endothelin in serial bronchial tissue sections from an Influenza A/PR-8/34 virus-infected mouse (day 2 postinoculation). The intense fluorescent immunostaining for a) endothelin was abolished by b) pre-absorption of primary antibody (anti-endothelin sera) with 100 $\mu \mathrm{M}$ of endothelin-2 for $3 \mathrm{~h}$ at $22^{\circ} \mathrm{C}$. c) no immunostaining was present in tissue sections prepared in the absence of primary antibody. Scale bar $=50 \mu \mathrm{m}$. lium of medium and small interpulmonary airways. In contrast, the majority of epithelial cells lining the trachea and bronchi were either not immunostained or displayed only weak immunostaining (figs. 4a and 5a).

Infection with Influenza A/PR-8/34 virus was associated with a marked increase in the intensity and distribution of fluorescent immunostaining for endothelin in lung tissue sections (figs. 4 and 5). At 2 days postinoculation, intense immunostaining for endothelin was present in the majority of epithelial cells lining the trachea and large virus-infected airways (figs. $4 \mathrm{~b}$ and $5 \mathrm{~b}$ ). At 4 days postinoculation, the epithelium of many large and medium sized airways also displayed intense immunostaining for endothelin (figs. 4c and 5d), consistent with the spread of viral infection to the peripheral respiratory tract. Furthermore, desquamated respiratory epithelial cells present in the lumen of many medium and small airways in these sections were also immunostained as were cells in pockets of inflammation in the peripheral lung (fig. 5d).

At 8 days postinoculation, in contrast to earlier time points, areas of inflammation were almost exclusively located in the peripheral lung of virus-inoculated mice. The epithelium of many small airways were intensely immunostained for endothelin (fig. 5f). Larger airways within these sections had a similar histological appearance to airways of a similar size in lung sections from control mice. Moreover, the low levels of immunostaining associated with the epithelial lining of these airways was similar to that observed in lung tissue sections from control mice (fig. 5e).

No immunostaining was present in tissue sections prepared in the absence of anti-endothelin sera (no primary antibody). Furthermore, pre-absorption of optimally diluted anti-endothelin sera (1 in 1,000) with endothelin-2 $(100 \mu \mathrm{M})$ abolished immunostaining of lung tissue sections (fig. 6).

\section{Discussion}

This study has clearly demonstrated increased levels and a broader distribution of immunoreactive endothelin in the lungs of mice during a respiratory tract infection with Influenza A/PR-8/34 virus. Importantly, the wider distribution of endothelin immunoreactivity was co-localized with histopathological signs of viral infection. While the early stages of infection ( 2 days postinoculation) were associated with a more uniform distribution of immunoreactive endothelin in the epithelium of large airways, more distal airways were increasingly involved with the passage of time. Together, these observations indicate that the changes in distribution and apparent intensity of immunostaining for endothelin in the airways of infected mice reflected the time course and spread of viral infection.

The current study has established that Influenza A/PR$8 / 34$ viral infection is associated with significantly elevated levels of the endothelins within the airways of mice, and we have recently established that this murine model of respiratory tract viral infection is also associated with the development of in vivo airways hyperresponsiveness (unpublished observations). The question as to whether the enhanced release of endothelin-1, coupled to the powerful effects of endothelin-1 on airway smooth 
muscle tone [21] and cholinergic neurotransmission [23] in murine airways, contributes significantly to virus-induced hyperresponsiveness must remain unanswered until definitive experiments using endothelin receptor antagonists or endothelin converting enzyme inhibitors have been completed. Nevertheless, an emerging role appears to exist for endothelin-1 in the production of the airways obstruction observed during allergen-induced lung inflammation. Antigen provocation of sensitized guinea-pigs produced a two-fold increase in bronchoalveolar lavage fluid levels of endothelin-1 [10], and moreover, the ad-ministration of endothelin receptor antagonists afforded significant protection against decreased airway conductance associated with antigen challenge [11]. These findings are consistent with the partial blockade produced by endothelin receptor antagonists of the hyperresponsiveness associated with the late response in allergic sheep [12]. Together, these observations suggest a potentially important role for endothelin- 1 in allergen and virus- induced airways hyperresponsiveness.

Clearly, an increase in endothelin content will only translate into augmented effects if the sensitivities of the respective endothelin receptor-effector systems are not down-regulated as a compensatory mechanism in response to the increase in endothelin content. We have previously investigated the influence of respiratory tract viral infection on endothelin receptor-effector systems in both airway smooth muscle $[21,24]$ and postganglionic cholinergic neurones [23]. Of particular interest, respiratory tract viral infection caused a transient decrease in the density of $\mathrm{ET}_{\mathrm{B}}$ receptors and in $\mathrm{ET}_{\mathrm{B}}$ receptor-mediated contraction in tracheal smooth muscle and it might be predicted that such a down-regulation of the $\mathrm{ET}_{\mathrm{B}}$ receptor-effector system would significantly attenuate the influence of any increase in endothelin content. However, we have recently established that both $\mathrm{ET}_{\mathrm{A}}$ and $\mathrm{ET}_{\mathrm{B}}$ receptors are linked to smooth muscle contraction in mouse trachea [21, 24]. Furthermore, the spasmogenic effects produced by a nonselective endothelin receptor agonist such as endothelin-1 are inhibited effectively only by the simultaneous blocking of both $\mathrm{ET}_{\mathrm{A}}$ and $\mathrm{ET}_{\mathrm{B}}$ receptors. Thus, although viral infection was associated with a marked down-regulation of the $\mathrm{ET}_{\mathrm{B}}$ receptor-effector system, contractile responses to exogenously applied endothelin1 were not attenuated because the $\mathrm{ET}_{\mathrm{A}}$ receptor-effector system remained fully functional. Similarly, endothelin-1 was equally effective at potentiating cholinergic nervemediated contractions of tracheal airway smooth muscle from control and virus-infected mice [23]. It would appear, therefore, that the increase in endothelin content observed in virus-infected mice will result in enhanced endothelin-induced effects in these animals.

The precise mechanism responsible for the increased levels of immunoreactive endothelin in the lungs of mice during viral infection is unknown. Although we have neither measured the level of messenger ribonucleic acid (mRNA) encoding endothelin precursor peptides, nor investigated the distribution of these precursor peptides in the airways of virus-infected mice, it is well established that several pro-inflammatory cytokines known to be released during respiratory tract viral infection [14] stimulate the synthesis and release of endothelin from isolated airway epithelial cells [15]. Consistent with this, the majority of immunoreactive endothelin present in the lungs of virus-infected mice was associated with airway epithelial cells. Thus, it is likely that the increased levels of immunoreactive endothelin in the lungs of virus-infected mice were due, at least in part, to enhanced production of endothelin by respiratory epithelial cells. Neutral endopeptidase appears to be the major enzyme involved in the degradation of the endothelins in the lung [4]. However, the activity of airway neutral endopeptidase is decreased by viral infection [25], raising the possibility that decreased breakdown, as well as increased synthesis, may contribute to the elevated levels of endothelin in the lungs of mice during viral infection.

In conclusion, the present study has clearly demonstrated an increased content and broader distribution of immunoreactive endothelin in the lungs of mice following intranasal inoculation with Influenza A/PR-8/34 virus. The altered distribution of immunoreactive endothelin mirrored the presence of inflammatory lesions in the airways and peripheral lung.

\begin{abstract}
Acknowledgements: The authors wish to acknowledge the late D. Springall, Dept of Histochemistry, Royal Postgraduate Medical School, London, for the generous gift of anti-endothelin sera. They also wish to thank S.H. Cody and P.J. Rigby, Biomedical Confocal Microscopy Research Centre, University of Western Australia, Nedlands, Australia, for their assistance in the preparation of photomicrographs.
\end{abstract}

\section{References}

1. Inoue A, Yanagisawa $\mathrm{M}$, Kimura $\mathrm{S}$, et al. The human endothelin family: three structurally and pharmacologically distinct isopeptides predicted by three separate genes. Proc Natl Acad Sci USA 1989; 86: 2863-2867.

2. Rozengurt N, Springall DR, Polak JM. Localization of endothelin-like immunoreactivity in airway epithelium of rats and mice. J Pathol 1990; 160: 5-8.

3. Ehrenreich, H, Anderson RW, Fox CH, et al. Endothelins, peptides with potent vasoactive properties, are produced by human macrophages. J Exp Med 1990; 172: 17411748 .

4. Goldie RG, Knott PG, Carr MJ, Hay DWP, Henry PJ. The endothelins in the pulmonary system. Pulm Pharmacol 1996; 9: 69-93.

5. Fernandes LB, Henry PJ, Rigby PJ, Goldie RG. Endothelin $_{B}\left(E_{B}\right)$ receptor activated potentiation of cholinergic nerve-mediated contraction in human bronchus. $\mathrm{Br} \mathrm{J}$ Pharmacol 1996; 118: 1873-1874.

6. Filep JG, Battistini B, Sirois P. Pharmacological modulation of endothelin-induced contraction of guinea-pig isolated airways and thromboxane release. Br J Pharmacol 1991; 103: 1633-1640.

7. Hay DWP, Henry PJ, Goldie RG. Is endothelin-1 a mediator in asthma? Am J Respir Crit Care Med 1996; 154: 1594-1597.

8. Mattoli S, Soloperto M, Marini M, Fasoli A. Levels of endothelin in the bronchoalveolar lavage fluid of patients with symptomatic asthma and reversible airflow obstruction. J Allergy Clin Immunol 1991; 88: 376-384.

9. Springall DR, Howarth PH, Counihan H, Djukanovic R, Holgate ST, Polak JM. Endothelin immunoreactivity of airway epithelium in asthmatic patients. Lancet 1991; 337: 697-701. 
10. Andersson SE, Zackrisson C, Behrens K, et al. Effect of allergen provocation on inflammatory cell profile and endothelin-like immunoreactivity in guinea-pig airways. Allergy 1995; 50: 349-358.

11. Uchida Y, Jum T, Ninomiya $\mathrm{H}$, et al. Involvement of endothelins in immediate and late asthmatic responses of guinea-pigs. J Pharmacol Exp Ther 1996; 277: 16221629.

12. Noguchi K, Ishikawa K, Yano M, Ahmed A, Cortes A, Abraham WM. Endothelin-1 contributes to antigen-induced airway hyperresponsiveness. J Appl Physiol 1995; 79: 700-705.

13. Stark JM, Graziano, FM. Lower airway response to virus. In: Busse WW, Holgate ST, eds. Asthma and Rhinitis. Massachusetts, Blackwell 1995; pp. 1229-1243.

14. Hennet T, Ziltener HJ, Frei K, Peterhans E. A kinetic study of immune mediators in the lungs of mice infected with influenza A virus. J Immunol 1992; 149: 932-939.

15. Endo T, Uchida $\mathrm{Y}$, Matsumoto $\mathrm{H}$, et al. Regulation of endothelin-1 synthesis in cultured guinea-pig airway epithelial cells by various cytokines. Biochem Biophys Res Commun 1992; 186: 1594-1599.

16. Williams K, MacKenzie JS. Influenza infections during pregnancy in the mouse. J Hygiene 1977; 79: 249-257.

17. Fazekas de St Groth S, White DO. An improved assay for the infectivity of influenza viruses. J Hygiene 1958; 56 : 151-162.

18. Potter CW, Oxford JS. Animal models of influenza virus infection as applied to the investigation of antiviral compounds. In: Oxford JS, ed. Chemoprophylaxis and Viral Infections of the Respiratory Tract. Cleveland, CRC Press, 1977; pp. 1-26.

19. Wong M, Jeng AY. Determination of tissue endothelin levels. Biochem Mol Biol Int 1995; 35: 1359-1364.

20. Wallenstein S, Zucker CL, Fleiss JL. Some statistical methods useful in circulation research. Circ Res 1980; 47: $1-9$.

21. Henry PJ, Goldie RG. $\mathrm{ET}_{\mathrm{B}}$ but not $\mathrm{ET}_{\mathrm{A}}$ receptor-mediated contractions to endothelin-1 attenuated by respiratory tract viral infection in mouse airways. Br J Pharmacol 1994; 112: 1188-1194.

22. Henry PJ, Rigby PJ, MacKenzie JS, Goldie RG. Effect of respiratory tract viral infection on murine airway $\beta$-adrenoceptor function, distribution and density. $\mathrm{Br} J$ Pharmacol 1991; 104: 914-921.

23. Carr MJ, Goldie RG, Henry PJ. Influence of respiratory tract viral infection on endothelin-1-induced potentiation of cholinergic nerve-mediated contraction in mouse trachea. Br J Pharmacol 1996; 119: 891-898.

24. Carr MJ, Goldie RG, Henry PJ. Time course of changes in $\mathrm{ET}_{\mathrm{B}}$ receptor density and function in tracheal airway smooth muscle during respiratory tract viral infection in mice. Br J Pharmacol 1996; 117: 1222-1228.

25. Jacoby DB, Tamaoki J, Borson DB, Nadel JA. Influenza infection causes airway hyperresponsiveness by decreasing enkephalinase. J Appl Physiol 1988; 64: 2653-2658. 